\title{
Evaluation of Ergonomic Conditions using Fuzzy Logic in a Metal Processing Plant
}

\author{
Tuğçe CAYMAZ ${ }^{1}$, Sümeyye ÇALIŞKAN ${ }^{2}$, A. Reha BOTSALI ${ }^{3, *}$ \\ ${ }^{1}$ Necmetin Erbakan University, Engineering and Architecture Faculty, Industrial Eng. Dept., Konya,Turkey \\ Email: tugcescaymaz@gmail.com ORCID: 0000-0002-5754-7475 \\ ${ }^{2}$ Necmetin Erbakan University, Engineering and Architecture Faculty, Industrial Eng. Dept., Konya,Turkey \\ Email: smyyeclskan6@gmail.com_ORCID: 0000-0002-0171-8976
}

${ }^{3}$ Necmetin Erbakan University, Engineering and Architecture Faculty, Industrial Eng. Dept., Konya,Turkey * Corresponding Author Email: rbotsali@erbakan.edu.tr ORCID: 0000-0002-8809-9353

\section{$\underline{\text { Article Info: }}$}

DOI: $10.22399 /$ ijcesen.932994

Received : 05 May 2021

Accepted : 05 March 2022

\section{$\underline{\text { Keywords }}$}

Fuzzy Logic

Ergonomy

Noise Level

Illumination

\begin{abstract}
:
Ergonomic conditions of workplace settings is important for the performance of companies. Especially in the manufacturing industry, the employees are required to have convenient workplace conditions. If this is not the case, it is most likely to have a decrease in work efficiency, increase in workload, and negative impacts on employee health. In this study, we evaluate two ergonomic conditions, illumination and noise level, in different departments of a metal processing plant, to find the initial department to work on the improvement of ergonomic conditions. The evaluation of ergonomic conditions is done through a fuzzification process. The quantitative measurement results of illumination and noise level are fuzzified by Mamdani method. The fuzzified measurement values are scored with respect to specified interval lengths. As a result of this scoring process, ergonomically the worst conditioned department is found to start the improvement process.
\end{abstract}

\section{Introduction}

Uncertainty is a common phenomenon almost in all fields of our lives and precise information is not available where uncertainty exists. The uncertainty and the lack of information result in subjective evaluations when we make decisions. Therefore we need an effective method to aid us in decision making and evaluation processes under uncertainty. At this point, using the fuzzy logic approach is a highly effective method for solving problems. An important difference of fuzzy logic from other logic systems is the use of linguistic variables.

Many terms that we use randomly in everyday life are often not clear and may refer to a concept, purpose or a system. In 1965, Lotfi A. Zadeh [1] developed a way of expressing this fuzziness. In his study, Zadeh put forward the fuzzy set theory of events with uncertain boundaries. With this development, the examination of systems containing uncertainty has gained a new dimension.
In short, fuzzy logic can be called a grading system. There is no probability of uncertainty, there are uncertainties related to human intuition. Fuzzy logic can be used to improve system performance, simplify the implementation of the process, and reduce cost. It does not require much manpower. There is also a general definition known as approximate reasoning. However, the most commonly used expression of fuzzy logic [2] is as follows:

"In fuzzy logic, values 1 and 0 are considered as bounds, not absolute values, and intermediate values are also used. In other words, assets can belong to more than one cluster, not a single cluster. For example, a fuzzy controlled washing machine can choose the most effective laundry and water usage program based on the type, quantity, and soiling of the laundry. Face recognition systems can also be given as examples."

The word ergonomics is derived from the Greek words ergon (work) and nomos (law). In many 
countries, the term 'human factors' is also used instead of ergonomics. Ergonomics can be expressed as the design of tools, technical systems, and works in a way to increase human health, safety, comfort, and performance. The official definition of ergonomics, approved by the International Association of Ergonomics (IEA), is as follows:

"Ergonomics (or human factors) is a scientific discipline, a field of pursuit that tries to understand the interaction between other elements of a system and people, and that applies theory, principles, knowledge, and methods that will optimize the overall system performance and human comfort. Ergonomics is the focus of the design of situations in business and daily life [3]."

Ergonomics is a science that ensures the adaptation of workers to today's aggravating and fast-paced working order by considering health factors. The first aim of ergonomics is to increase the efficiency of worker-machine combination and worker health. Since lifting, holding, and carrying activities can tire a person very quickly and cause serious health problems, a lot of research has been done on this subject and it is still going on [4]. Ergonomic conditions are important for increased work efficiency and for employees to work safely and healthily. For this reason, ergonomic risk analysis of defined work activities should be done, the factors that cause physical strain on the human should be determined, and necessary corrective measures should be defined to eliminate these factors [5]. In a competitive environment, businesses must effectively manage and direct production inputs such as raw materials, energy, labor, and the capital. It is clear that among these inputs, the workforce (employees) has an important place. Besides, work arrangements of employees directly affect production efficiency [6].

The main purpose in the ergonomic study of work environments is not only to ensure the health and safety of employees, but also to establish a working environment where employees can put their physical and psychological abilities in the most effective way. By this way, it is possible to increase the efficiency of the employees and the quality of the work done [7].

In this study, investigations are made in a metal factory regarding lighting and noise conditions. Measurements of these two variables are made for each department. Then measurements are expressed and fuzzified with linguistic data. According to the results of the evaluation, we determine the department for which the ergonomic improvement studies should start.

\section{Methodology}

This study is done for a plant located in Ankara Ostim Industry Area. The plant has three workshops and production areas. It provides sheet cutting service in its workshops and provides project design, sheet cutting, bending, welding, painting, and assembly services as a whole. The measurement was carried out at three different departments of the plant: laser-1, welding- 1 and welding-3.

\subsection{Measurement of Physical Conditions}

For two different criteria, illumination and noise levels, the measurements are taken for the three departments in the plant. The devices used for the measurement processes and the factors taken into consideration are explained below:

Extech SDL400 light meter / data logger device is used during the illumination level measurements (Figure 1) It is capable of measuring up to $10,000 \mathrm{Fc}$ or $100 \mathrm{kLux}$. Illumination level measurements are taken by keeping the device sensor parallel to the working floor through the field of vision. During the noise level measurements, the device receiver is placed close to the ear of the employee and the employee is requested to have his daily working tempo, not to turn off the lapel microphone, Measurements are made with SL355: Personal Noise Dosimeter / Datalogger device (Figure 2). The device is verified both before and after measurements with the TES 1356 Sound calibrator (Figure 3). The exposure is calculated by taking three measurements for each task.

\subsection{Data}

As mentioned in the previous section, measurements are taken for two different

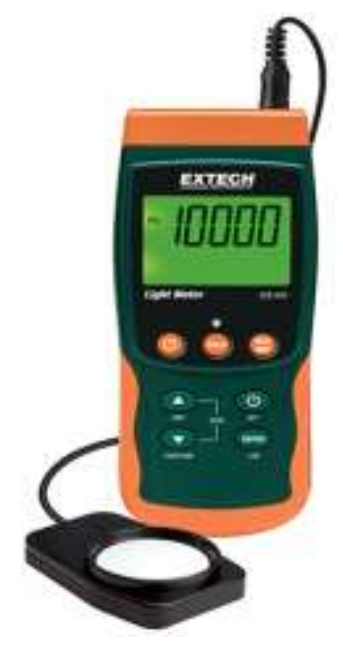

Figure 1. Light meter 


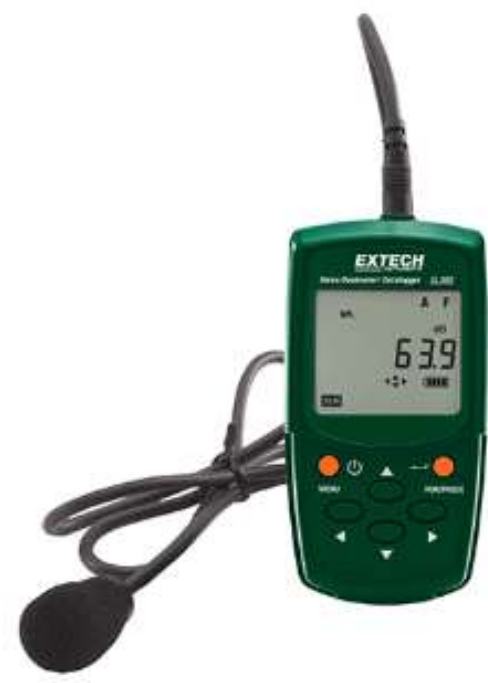

Figure 2. SL355: Personal Noise Dosimeter/Datalogger

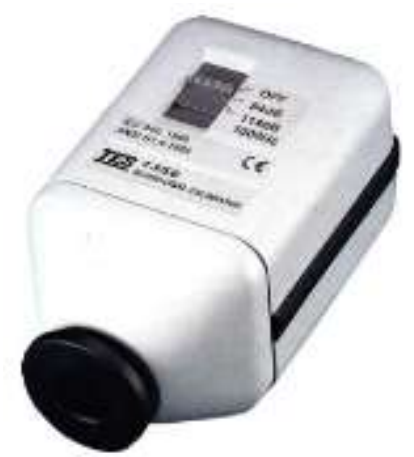

Figure 3. TES 1356 Sound Calibrator ergonomic variables (noise and illumination levels) from three different departments in the plant. The average values of the measurements for each department are given in table 1 . In order to evaluate the measurement values with fuzzy logic, three linguistic variables, "bad", "average" and "good" are determined for each ergonomic factor.

Table 1. Average values of the measurements

\begin{tabular}{|l|r|r|r|}
\hline & Laser 1 & Welding 1 & Welding 2 \\
\hline Noise & $91,1 \mathrm{~dB}(\mathrm{~A})$ & $94,3 \mathrm{~dB}(\mathrm{~A})$ & $88,4 \mathrm{~dB}(\mathrm{~A})$ \\
\hline Illumination & 857 & 712 & 575 \\
\hline
\end{tabular}

The evaluations regarding noise are made in accordance with the Regulation No. 28721 on the Protection of Employees from Risks Related to Noise, which is published in the Official Gazette on $28 / 07 / 2013$. For evaluating the measurement results of the plant, 8 hours/day work time is taken as the basis of the noise exposure in accordance with the physical conditions of the plant from the values of Noise Control Regulation in table 2.

Table 2. Noise level control regulation [8]

\begin{tabular}{|l|l|}
\hline Lowest exposure action value & $($ LEX, 8hours $)=80 \mathrm{~dB}(\mathrm{~A})$ \\
\hline Highest exposure action value & $(\mathrm{LEX}$, 8hours $)=85 \mathrm{~dB}(\mathrm{~A})$ \\
\hline Exposure limit value & (LEX, 8hours $)=87 \mathrm{~dB}(\mathrm{~A})$ \\
\hline
\end{tabular}

Illumination measurements are taken during the day. Recommended illumination levels are given in table 3. Minimum illumination level is based on 700 lux.

Table 3. Lower values of the recommended intensity of illumination (Taken from [9])

\begin{tabular}{|l|l|l|}
\hline \multicolumn{1}{|c|}{ Vision Type } & \multicolumn{1}{|c|}{$\begin{array}{c}\text { Least Light Intensity at the } \\
\text { Location (LUX)* }\end{array}$} & \multicolumn{1}{c|}{ Typical Examples } \\
\hline General & $20-100 \mathrm{Lux}$ & $\begin{array}{l}\text { Boiler room (Coal and ash removal tasks), coarse material } \\
\text { warehouses, storage, dressing places. }\end{array}$ \\
\hline Rough & $150 \mathrm{Lux}$ & $\begin{array}{l}\text { Rough tasks and sorting tasks on work desks and benches, } \\
\text { general examination and counting of stored materials, } \\
\text { assembly of heavy machinery. }\end{array}$ \\
\hline Pretty critical & 300 Lux & $\begin{array}{l}\text { Moderately hard tasks at work desks and benches, as well as } \\
\text { assembly and control jobs, general office work, literacy and } \\
\text { recording jobs. }\end{array}$ \\
\hline Critical & 700 Lux & $\begin{array}{l}\text { Sensitive tasks on work desks and benches, assembly and } \\
\text { control tasks, very delicate dyeing tasks, sewing of dark } \\
\text { fabrics. }\end{array}$ \\
\hline Very critical & 1500 Lux & $\begin{array}{l}\text { Assembly and control of sensitive parts, tool and gauge } \\
\text { production, their control, sensitive grinding work. }\end{array}$ \\
\hline $\begin{array}{l}\text { Very difficult or } \\
\text { important }\end{array}$ & 3000 Lux & Watch making and repair work or similar sensitive tasks. \\
\hline
\end{tabular}




\subsection{Application of Fuzzy Logic}

Membership functions and fuzzy ranges of the linguistic assessment, which we named as "bad", "average", and "good" for two different physical conditions are determined according to the given limit values in tables 2 and 3. This process is done separately for each department depending on the requirements of the departmental tasks. Triangle and trapezoid membership functions are used in definitions of membership functions, as is frequently used in the literature. Examples for the triangular and trapezoidal membership function are shown in figures 4 and 5, respectively [10].

$$
\mu\left(\frac{x}{\tilde{M}}\right)\left\{\begin{array}{c}
0, \quad x<a_{1}, \\
\frac{x-a_{1}}{a_{2}-a_{1}}, a_{1} \leq x \leq a_{2}, \\
\frac{a_{3}-x}{a_{3}-a_{2}}, \quad a_{2} \leq x \leq a_{3}, \\
0, \quad x>a_{3},
\end{array}\right.
$$

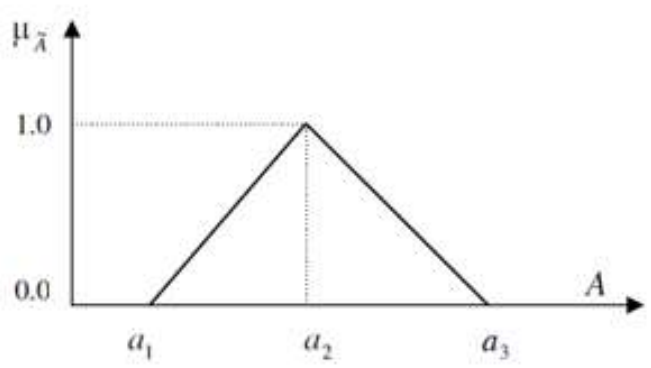

Figure 4. Triangular membership function

$$
\mu_{\tilde{\mathrm{A}}}(\mathrm{x})=\left\{\begin{aligned}
0, & x<a_{1} \\
\frac{x-a_{1}}{a_{2}-a_{1}}, & a_{1} \leq x \leq a_{2} \\
1, & a_{2} \leq x \leq a_{3} \\
\frac{x-a_{4}}{a_{3}-a_{4}}, & a_{3} \leq x \leq a_{4} \\
0, & x>a_{4}
\end{aligned}\right.
$$

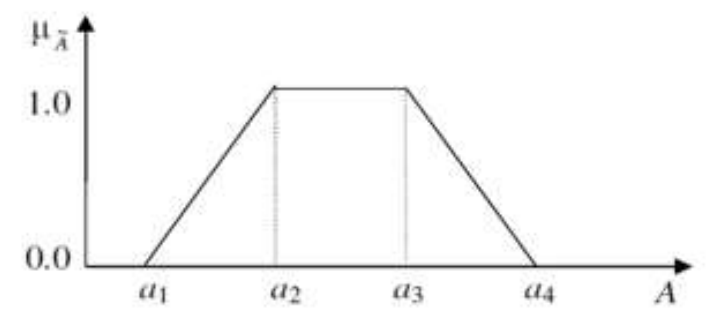

Figure 5. Trapezoidal membership function
In figure 4 , for the triangular membership function $\mu_{\tilde{A}}(x), a_{1}$ and $a_{3}$ show the base of the triangle, and $a_{2}$ show the peak value. In figure 5 , for the trapezoidal membership function $\mu_{\tilde{A}}(x), a_{1}, a_{2}$, $a_{3}$, and $a_{4}$ correspond to lower limit, lower support limit, upper support limit, and upper limit, respectively.

Use of fuzzy logic for ergonomics is a common method in the literature. (Ex. [11], [12]). In this study, for the fuzzy logic evaluation, "Mamdani Method" which is the most applied fuzzy inference method was used. This method was developed by Ebrahim Mamdani in 1974 [13]. This novel notion provides a fuzzy control that is "model free" and it does not require a system's mathematical model to be available. The model is not needed partially because the system's behavior is, to a large extent, captured and represented in a vague fashion in the forms of fuzzy sets and fuzzy control rules provided by the human control expert. In other words, the model information was integrated into the fuzzy controller [14]. The Mamdani's method has a simple structure of min-max operations and is, therefore, very commonly used in applications.

The fuzzy inference process comprises four subsequent steps: evaluating the antecedent for each rule, obtaining a conclusion for each rule, aggregating all conclusions, and finally defuzzifying [15].

All the operations related to fuzzy logic application have been carried out in MATLAB software. Considering the standard values for the physical conditions given above, individual membership functions are defined for each ergonomic variable. The membership function plots for illumination and noise level variables are given in figures 6 and 7 , respectively. As seen in these plots, illumination levels above 700 Lux and noise levels below 80 $\mathrm{db}(\mathrm{A})$ can be in good category.

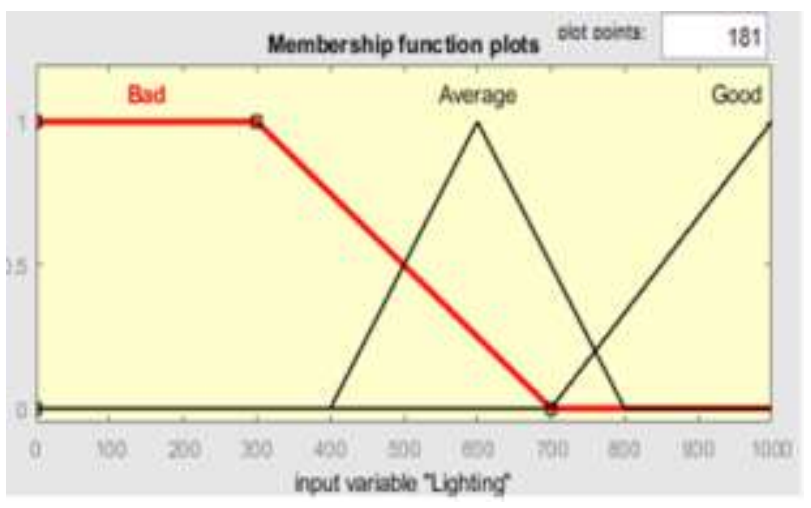

Figure 6. Illumination level membership function 


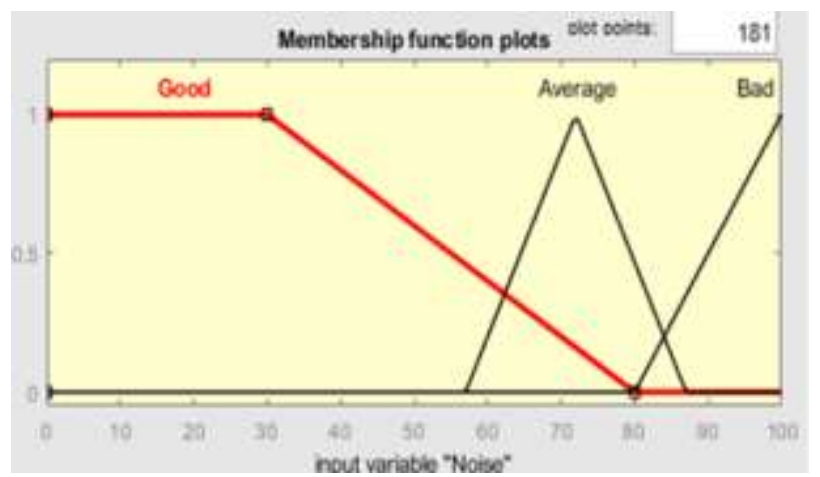

Figure 7. Noise level membership function

After determining the membership function types and definitions to be used in the calculations, the types and definitions of the output functions for the departments to be evaluated are determined (Figure 8). The output function is formed with trapezoidal membership functions with an evaluation range of $0-100$. The linguistic expressions for evaluation were created in 5 different classifications: "very bad", "bad", "average", "good" and "very good".

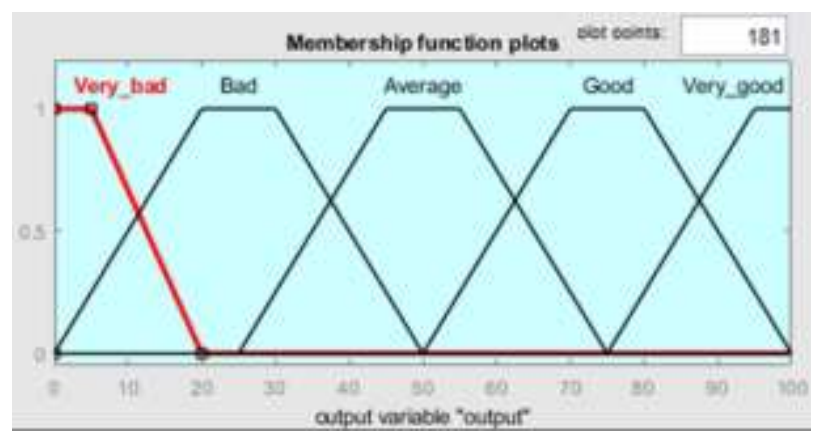

Figure 8. Output functions

Fuzzy rules are determined to provide all the conditions that may occur after all the input and output functions are created. These rules are again expressed in terms of linguistic variables. As seen in table 4, three different linguistic evaluations for membership function, two different variables for physical conditions and $32=9$ conditions were created. Centroid method is chosen for defuzzification in the study.

\section{Results}

For each department, the arithmetic mean values of ergonomic variables are entered in MATLAB Fuzzy Toolbox and the results are obtained (Figure 9). With the help of "Centroid" method, a net value in the range of $0-100$ is obtained for each department. These values are given in table 5. By ordering these results from the lowest to the highest, we determine the order of departments to
Table 4. Fuzzy conditions table (A=Average, V=Very, $B=B a d, G=G o o d)$

\begin{tabular}{|c|c|c|c|c|}
\hline & \multicolumn{3}{|c|}{ Noise Level } \\
\hline & & Bad & Avg. & Good \\
\hline \multirow{3}{*}{ 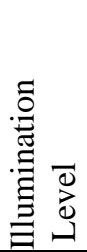 } & Bad & V.B & B & A \\
\hline & Avg. & B & A & $\mathrm{G}$ \\
\hline & Good & A & $\mathrm{G}$ & V.G \\
\hline
\end{tabular}

start the improvement studies in physical conditions. As seen in table 5, Laser 1 department is in good condition with an evaluation score of 51.2 compared to the welding departments. Although both welding departments have close evaluation scores (23.6 and 26.9), since Welding 3 department has the lowest score, it is necessary to give the priority to Welding 3 department for improvement studies. Also considering that Welding 1 department has also a low evaluation score (26.9), the improvement studies for this department should not be delayed much, either.

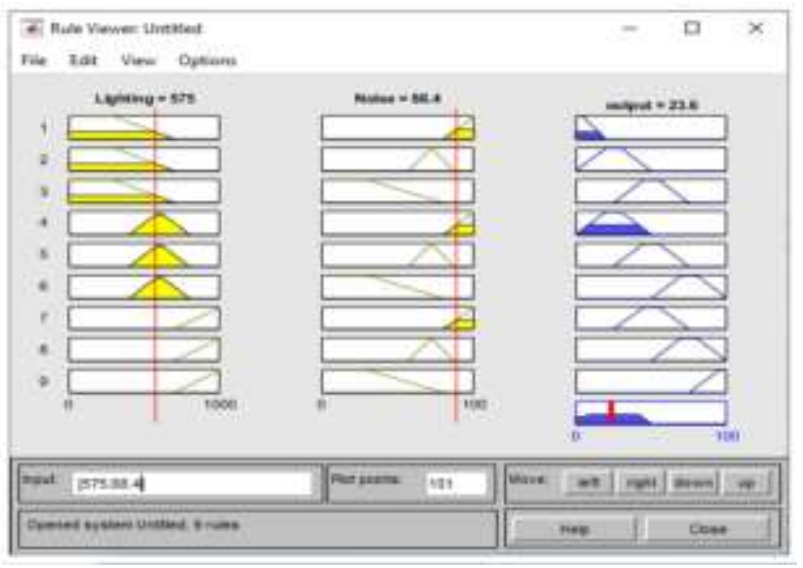

Figure 9. MATLAB fuzzy toolbox image

Table 5. Priority decision table for improvements

\begin{tabular}{|c|c|c|}
\hline Departments & Evaluation Score & Priority \\
\hline Laser 1 & 51.2 & 3 \\
\hline Welding 1 & 26.9 & 2 \\
\hline Welding 3 & 23.6 & 1 \\
\hline
\end{tabular}

\section{Conclusions}

In this study, we evaluate the working conditions in three departments of a plant in terms of illumination and noise level ergonomic variables. Taking several measurements from these three departments, numerical measurement values are obtained. Then using Mamdani method and 
MATLAB Fuzzy Toolbox, evaluation scores for each department is obtained. If a department gets a lower score, this shows that the department needs immediate attention for improvement. This study can be extended to by increasing the number of departments. Also other environmental variables like temperature, humidity, weather quality can be included in the analysis of working conditions.

\section{Author Statements:}

- Ethical approval: The conducted research is not related to either human or animal use.

- Conflict of interest: The authors declare that they have no known competing financial interests or personal relationships that could have appeared to influence the work reported in this paper

- Acknowledgement: The authors declare that they have nobody or no-company to acknowledge.

- Author contributions: The authors declare that they have equal right on this paper.

- Funding information: The authors declare that there is no funding to be acknowledged.

- Data availability statement: The data that support the findings of this study are available on request from the corresponding author. The data are not publicly available due to privacy or ethical restrictions.

\section{References}

[1] Zadeh L.A., (1965). Fuzzy sets. Information and Control. 8(3):338-353. DOI: 10.1016/S00199958(65)90241-X

[2] Li D. F. and J.-B-. Yang. (2004). Fuzzy linear programming technique for multiattribute group decision making in fuzzy environments. Inf. Sci. (Ny). 158:263-275.

DOI: $10.1016 /$ j.ins.2003.08.007

[3] Çalışkan M. and F. Fındık. (2012). Malzeme, Ergonomi Ve Biyomekanik İlişskisi. Sakarya Üniv. Fen Bilim. Enstitüsü Derg. 16(3):273-282. DOI: 10.16984/saufbed.08867

[4] Coşkun M.B., H. Sağıroğlu, and N. Erginel, (2015) İş İstasyonlarının Ergonomik Riskinin Niosh Yöntemi İle Belirlenmesi. Mühendislik Bilim. ve Tasarım Derg., 3(3):365-370.

[5] Alkan E. and M. A. Ilgın, (2018), Bir Elektronik Firmasının Montaj Hatlarının Ergonomik Analizi. Ömer Halisdemir Üniversitesi Mühendislik Bilim. Derg., 7(1):149-158.

DOI: $10.28948 /$ ngumuh.386385

[6] Can G. F., K. D. Atalay, and E. Eraslan, (2015). Working Posture Analysis in Fuzzy Environment and
Ergonomic Work Station Design Recommendations. Journal of the Faculty of Engineering and Architecture of Gazi University 30:451-460

[7] Güner M., A.. İlleez, and C. Ünal, (2009), Evaluation of Plant's Physical Conditions Using Fuzzy Logic: An Apparel Industry Case Study, Tekst. ve Konfeksiyon, 19(3):206-211.

[8] Başbakanlık Mevzuatı Geliştirme ve Yayın Genel Müdürlüğü. (Accessed: 29-Jan-2021) https://www.resmigazete.gov.tr/eskiler/2013/07/2013 0728-11.htm

[9] Güner M. A., A. A. İlleez, Konfeksiyon İşletmeleri Kalite Kontrol Departmanlarındaki Aydınlatma Seviyeleri, TMOBB Elekrik Mühendisleri Odası. https://www.emo.org.tr/ekler/051430a15d3d44d_ek.pdf

[10] Özkan M., (2003), Bulanık Hedef Programlama. Ekin Kitabevi

[11] Aluclu I., A. Dalgic and Z.F. Toprak, (2008), A Fuzzy Logic-based Model for Noise Control at Industrial Workplaces, Applied Ergonomics, 39:368378. DOI: 10.1016/j.apergo.2007.08.005

[12] Taqizade S., H. Eskandari, I. Alimohammadi and F. Jaderi, (2014), A fuzzy expert system for selection of an effective method for noise reduction in a petrochemical complex, Noise Control Engineering Journal, 62:344-353.

[13] Mamdani E.H. and S. Assilian, (1975), An experiment in linguistic synthesis with a fuzzy logic controller, International Journal of Man-Machine Studies, 7(1):1-13. DOI: 10.1016/S00207373(75)80002-2

[14] Zhou H. and H. Ying, (2013), A method for deriving the analytical structure of a broad class of typical interval type-2 Mamdani fuzzy controllers, IEEE Trans. Fuzzy Syst., 21(3):447-458. DOI: 10.1109/TFUZZ.2012.2226891

[15] Sanchez-Torrubia M.G., C. Torres-Blanc, and S. Krishnankutty, (2006), Analyzing and applying computer algebraic systems to engineering education: WSEAS Transactions on Advances in Engineering Education, 3:977-983. 